Roughly the first quarter of the book covers woodland classification, soils, plant and tree communities; in some measure this overlaps with Peterken but the emphasis on man's role in shaping the woods gives a usefully different slant. Evidence from pollen analysis, soil structure, earthworks and archaeological remains, vegetation and tree rings, oral tradition, paintings and written records is brought together to present woodlands not only as places of beauty, rich in wildlife, but also as a part of our heritage - as much a reflection of past human skills, aspirations and shifts of power as any cathedral.

Moving on to the human uses of woods, the author leads us from Neolithic times through the extensive records of Domesday to

the mad world of the 1970s, in which the price of ordinary oak-trees is as low, in relation to the value of money, as at any time since the fifteenth century; the price of oak timber is higher, again in relative terms, than at any time in history; and prices paid for underwood, provided the seller knows where to find the buyer, seem to be roughly equal to the previous all-time maximum in the eighteenth century.

Nearly half of the text deals with individual tree species, examining their distribution, prehistory and history, modern ecology and conservation. With many references to specific sites, one is presented with the opportunity to go and see for oneself - a temptation I will certainly find irresistible when the sun shines, just as dipping into the book will be a continuing pleasure on rainy days.

John Andrews is Head of Conservation Planning at the Royal Society for the Protection of Birds, Sandy, Bedfordshire.

\title{
The malaise of modern medicine?
}

\section{Robin Weiss}

The Diseases of Civilisation. By Brian Inglis. Pp.371. ISBN 0-340-21717-0. (Hodder \& Stoughton:1981.) £10.95.

BRIAN Inglis is a respected journalist and author who has written several informative books on the history of medical practice, orthodox, homeopathic and supernatural. His latest, The Diseases of Civilisation, is subtitled "An indictment of traditional methods of medical treatment and a plea for a completely new approach". Inglis surveys the major diseases affecting the Western world today - heart disease, cancer, mental illness, common infections, "auto-immune" and degenerative diseases - and concludes that modern medical science and practice has failed to live up to the high hopes of the immediate post-War period. Rather than question how realistic these expectations ever were, generated by journalists like himself as much as by the medical profession, Inglis concludes that the medical establishment is to blame for the intractability of ill-health in modern times. He depicts the medical profession as a self-perpetuating oligarchy composed of too many narrow specialities which dominates medical education and research, distorting both to serve its own ends and thereby obstructing public health. The food, tobacco and pharmaceutical industries are the accomplices in this medical crime, abetted by Governments that shy away from confrontation with an entrenched medico-industrial complex. Inglis argues that this unholy alliance has prevented the medical profession from embracing and acting upon discoveries of the important roles of diet, stress and other social factors in the causation of disease, so that resources which should be channelled into primary health care are deflected into the ever-increasing expense of high technology hospital treatment.

Much of this argument is regrettably only too true. The medical establishment is extremely conservative and profoundly suspicious of social or "unorthodox" approaches to disease. As Thomas McKeown has long argued, medical education is almost entirely geared to the treatment of acute illness as presented in teaching hospitals; the underlying causes of disease, other than specific pathogens, receive scant attention and the very concept of health is hardly raised during the training of doctors. Governments faced with butter mountains and tobacco revenues usually duck environmental and health issues when confronted by powerful lobbies - witness President Carter dismissing $\mathrm{Mr}$ Califano from the Department of Health, Education and Welfare, and Mrs Thatcher reshuffling Sir George Young out of the Department of Health and Social Security as soon as they tried to take significant action on curbing the promotion of cigarette consumption.

Brian Inglis has tackled a most important subject - the limitations and misconceptions in the modern Western approach to illness and health - yet I find his book disappointing and his message pernicious. Posing as a carefully researched documentary, it is more a polemical tract in the tradition of Ivan Illich's Medical Nemesis in which Inglis overstates his case to the point of being anti-science. His main thesis is that psychosocial stress is not taken into account in the investigation, management and prevention of diseases of civilization. He cites Stewart Wolf's important finding that heart disease hardly occurred in Roseto, Pennsylvania, while the inhabitants maintained a cohesive, conservative society, although they ate a typical Western diet. Wolf himself in Social Environment and Health (University of Washington Press, 1981) views disease as maladaptation to changing social conditions. Inglis concludes that it is therefore wrong to treat disease by orthodox methods. He proceeds to select the failures of modern health care and to ignore all the successes. He would have us believe that all heart surgery is a wasted resource, that no cancer patients benefit from chemotherapy, that mental hospitals should be abolished and that immunization plays little role in preventing infectious diseases. He states that "the net value of orthodox medical treatment is far less than it was twenty-five years ago, and is declining".

The chapters I find most objectionable, no doubt because they deal with my own subjects of study, are on infectious diseases and on cancer. Inglis dismisses research into the identification and control of infectious agents in disease (for example in Legionnaires' disease and in malaria) as "'mechanistic heresy" obscuring psychosocial elements. He also shows a remarkable prejudice against virologists, imagining that they narrowly pursue infectious organisms without reference to epidemiology and pathogenesis. Elsewhere he supposes that virologists have sought to monopolize cancer research, preventing immunologists investigating "cancer immunotherapy", whereas it is the virusinduced cancers that may yield first to immunological means of prevention or therapy. The eradication of smallpox, the resounding medical triumph of the 1970s, is not cited at all in Inglis's book, yet its success depended on the very combination of preventive vaccination and thorough epidemiological investigation that orthodox medicine provided where 2,000 years of ayurvedic methods in India failed. The successful outcome of virological research leading to immunization against poliomyelitis earns a grudging mention, with the extraordinary suggestion that the rare but devastating neurological damage caused by polio virus infection is more related to psychosocial stress than to the virulence of the virus strain. Polio and infectious mononucleosis are two particularly intriguing diseases of civilization in that children of the higher social classes are the ones most at risk; the epidemiological factors underlying this phenomenon are not probed by Inglis, presumably because they do not fit his view of how virologists conduct research.

Inglis's criticisms of orthodox cancer treatment resemble those which have recently occupied the columns of the Washington Post and the diatribe by Dick Richards (The Topic of Cancer: When the Killing Has to Stop; Pergamon, 1982) against those who "cut, burn and poison" 
cancer patients. Few would deny that patients sometimes receive excessive or inappropriate treatment; but having berated specialities, Inglis does not see that this is most likely to happen when cancer patients are treated by non-specialists. Inglis blames the medical establishment for the lack of progress in treating cancers of the lung and breast. Yet he makes no reference whatsoever to the successful treatment and cure of many paediatric cancers and leukaemia, Hodgkin's disease, choriocarcinoma or testicular cancer, which all result from the development of the aggressive forms of therapy which he so derides. True, these are rare types of cancer in terms of total incidence of malignant disease; but they are major causes of serious illness in children and young adults, with a high social and personal toll. There are common cancers too - of the skin, for example - for which diagnosis at an early stage undoubtedly reduces mortality very significantly. Inglis also entirely ignores palliative treatment, assuming that surgery, radiotherapy, chemotherapy or endocrine treatment invariably cause more suffering than leaving the cancer patient untreated by orthodox methods.

Inglis's account of cancer research funding policy is also seriously misinformed. He states that because the British cancer research charities "are largely controlled by specialists, naturally they favour projects which help them in their hospital work, providing them with better-equipped operating theatres, improved radiotherapy machines, more powerful drugs"'. This is nonsense, as no research project is more difficult to obtain funding for than one that smacks of a medical service role. Following the British Medical Journal's peculiar outburst two years ago, Inglis reiterates that less than 2 per cent of the British charities' expenditure is directed towards research into cancer epidemiology and prevention, an absurd underestimate even if one discounts the potential of basic research for future prevention. He thinks the public should be given more opportunity to influence the way in which cancer research funds are spent. This is a laudable sentiment, though difficult to implement;

\section{Handlist for historians}

The Science Museum, London, has recently published a vade-mecum for science historians, Reference Books for the Historian of Science: $A$ Handlist. The bibliography has been compiled by S.A. Jayawardene with the intention of providing a volume to complement other bibliographic manuals, covering the primary and secondary sources of the history of science, by the inclusion of general reference books. The handlisi includes some 1,000 titles, and is available from Library Publications, Science Museum Library, South Kensington, London SW7 5NH, price $£ 2.50$, $£ 3$ by post. moreover, "the public" will almost always choose to fund high-technology hardware, such as CT scanners, in preference to research into the psychosocial aspects of cancer that Inglis rightly wishes to promote.

In criticizing the medical management of the mental patient Inglis is on stronger ground, in that no single orthodoxy has emerged. From his account one does have the feeling that the theory and practice of treatment for mental illness has not advanced beyond the blood-letting era. Having heaped scorn upon the medical establishment's "obsession with diagnosis" for infectious diseases, Inglis here deplores the unreliable classification of mental disease, quoting large discrepancies between US and British psychiatrists. In fact, the WHO definition of schizophrenia can now be used to standardize diagnosis. As Julian Leff discusses in his recent monograph Psychiatry Around the Globe: A Transcultural View (for review see p.523), the incidence of schizophrenia is surprisingly uniform across different cultures, though its recognition as a disease state requiring treatment differs widely.

Inglis misses another opportunity for serious debate in his chapter on iatrogenic disorders. Quoting the Hippocratic dictum "At least, do no harm", he does not discuss whether the harm induced by treatment might be less than that of no treatment. Inglis justly reproaches the medical profession over drug abuse and carefree prescription, particularly in treating the symptoms of diseases of civilization without paying due attention to underlying causes. Yet in an earlier chapter he criticizes by-pass surgery for angina pectoris when chronic drug treatment might achieve the same result. One of the most notorious examples of iatrogenic disease (not quoted by Inglis) was the induction of leukaemia in patients treated with X-irradiation for ankylosing spondylitis. The radiotherapy undoubtedly caused enormous relief from the symptoms of a crippling, painful and eventually fatal hereditary disease; given the prospect of that relief, with the possibility of dying from iatrogenic leukaemia 15 years later, would Inglis have advised the spondylitis patient to spurn treatment?

Overall, Inglis has broached an important topic by questioning the basis of our current medical philosophy and its disregard for preventative health measures and social care. But I wish that he had not chosen to present orthodox medicine and research as the antithesis of genuine care and that he had researched his commentary more deeply. More importantly, I earnestly hope that any young man with testicular cancer or parent with a chiid suffering from leukaemia will not refuse orthodox treatment as a result of reading this book. $\quad \square$

Robin Weiss is Director of the Institute for Cancer Research, London.

\section{Politics of pesticides}

\author{
M.S. Swaminathan
}

Circle of Poison: Pesticides and People in a Hungry World. By David Weir and Mark Schapiro. Pp.99. ISBN 0-935028-09-9. (Institute for Food and Development Policy/Third World Publications: 1981.) $\$ 3.95, £ 2.50$.

Circle of Poison provides an insight into the process by which "someone in the underdeveloped countries is poisoned by pesticides every minute". The circle begins with the activities of leading multi-national corporations which dominate the sevenbillion-dollar-a-year pesticide market. The links in the chain include loopholes in government regulations in the United States, the import policies of developing countries and the indifference of bilateral and multilateral donors, regional and international banks and UN agencies.

Weir and Schapiro argue their case cogently. For example they point out that at least 25 per cent of US pesticide exports are products that are banned, heavily restricted or have never been registered for use in the United States - "The Federal Insecticide, Fungicide and Rodenticide Act explicitly states that banned or unregistered pesticides are legal for export". Developing countries which receive hazardous pesticides recommend the application of such pesticides in a routine manner, partly due to ignorance and partly due to their being cheaper than less-toxic products. An instance has been cited where parathion is being used in Central America at a dosage 40 per cent greater than necessary. In contrast, through the adoption of better pest-management procedures, US farmers now use $35-50$ per cent less insecticide than ten years ago, with no adverse effect on crop yield. An important consequence of the indiscriminate use of pesticides is the multiplication of pesticide-resistant insect species, leading to the use of still higher concentrations of the chemical, and so on.

At each stage in the process, the circle of poison has its victims - the staff in pesticide manufacturing plants, those who load and unload the chemicals, Third World peasants, workers and consumers, and finally everyone else in the world who eats food contaminated with pesticide residues. But undoubtedly the greatest impact is felt in the developing nations. According to some calculations, the rate of pesticide poisoning in such countries is more than 13 times that in the USA. The authors give examples from their investigations in Mexico, Central America, Pakistan, Indonesia and Papua New Guinea to illustrate how pesticides prohibited in the US reach the peasants of the Third World. Unfortunately, in these countries there are neither enough scientists to investigate the dangers arising from such pesticides nor is there a well- 